\title{
Therapeutic Effect of Thyme (Thymus Vulgaris) Essential Oil on Patients with COVID19: A Randomized Clinical Trial
}

\author{
Saeed Sardari ${ }^{1 \text { (D), Ahmadreza Mobaien }}{ }^{2}$, Leila Ghassemifard ${ }^{1}$ (D), \\ Koorosh Kamali $^{* * i D}$, Narjes Khavasi ${ }^{1 *}$ iD
}

1. Dept. of Persian Medicine, School of Medicine, Zanjan University of Medical Sciences, Zanjan, Iran

2. Dept. of Infectious Diseases, Vali-e-Asr Hospital, School of Medicine, Zanjan University of Medical Sciences, Zanjan, Iran

3. Social Determinants of Health Research Center, Zanjan University of Medical Sciences, Zanjan, Iran

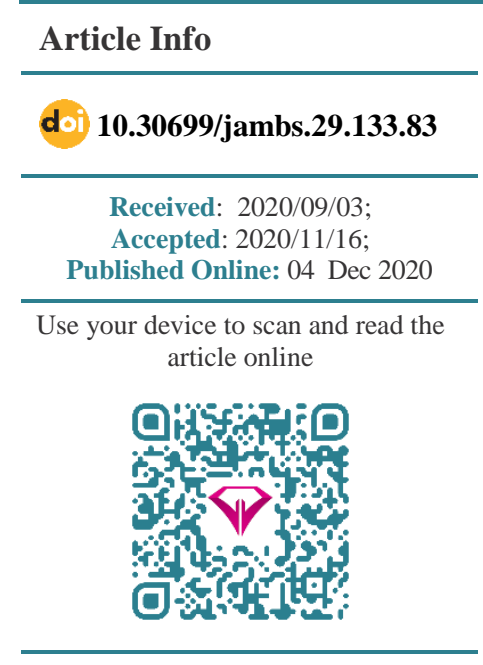

Corresponding Information: Narjes Khavasi,

Dept. of Persian Medicine, School of

Medicine, Zanjan University of

Medical Sciences, Zanjan, Iran

E-Mail:

nxavasi@zums.ac.ir

\begin{abstract}
Background \& Objective: Severe acute respiratory syndrome coronavirus 2 (SARS-CoV-2) is a worldwide pandemic disease. There is currently no effective cure for this virus, but some types of herbs can be a good choice for reducing its symptoms. There are some reports that Thymus vulgaris has high antioxidant compounds effective in strengthening the immune system, as well as antiviral effects in reducing the respiratory symptoms. Therefore, we speculated that $T$. vulgaris could be useful for reducing some of the symptoms in patients suffering from coronavirus disease 2019 (COVID-19).
\end{abstract}

Materials \& Methods: First, thyme essential oil was prepared, and a questionnaire regarding the patients' symptoms was designed. Then, 83 patients with COVID-19 were randomly selected and divided into control and thyme-receiving groups. The questionnaire was completed and emphasized to consume $5 \mathrm{~mL}$ of the syrup or essential oil three times per day. Finally, one week after the first visit, the questionnaire was completed again to determine the effects of thyme on the mentioned symptoms. Then, the test results were reviewed and reported.

Results: The results one week after taking thyme showed that the fever $(P<0.027)$, dizziness $(P<0.003)$, cough, dyspnea, muscular pain, headache, anorexia, weakness and lethargy, fatigue, and chest wall pain were significantly reduced $(P<0.001)$. Also, blood urea nitrogen (BUN) $(P<0.004)$, neutrophil count $(P<0.001)$, and calcium were $(P<0.034)$ decreased, but lymphocyte count was increased significantly $(P<0.001)$.

Conclusion: Thyme plant, which has high antioxidant properties, strengthens the immune system, and by inducing the antiviral effect could reduce the symptoms of coronavirus; therefore, it is recommended for reducing the symptoms of COVID-19.

Keywords: Coronavirus disease 2019, Thyme, Thymus vulgaris, Persian medicine,

\section{Introduction}

Coronaviruses were first identified in 1960 (1), and animals are said to be the main source of these viruses $(2,3)$. More than 8000 people were infected with this virus, and 774 virus-related deaths with severe acute respiratory syndrome (SARS) were reported in 2002 and 2003. Since September 2012, there have been 2494 cases of Middle East respiratory syndrome coronavirus (MERS-CoV), and 858 deaths from this virus have been reported to the World Health Organization (WHO) (4, 5). In 2019, the new generation virus was named severe acute respiratory syndrome coronavirus 2 (SARS-CoV-2), and the resulted disease was named coronavirus disease 2019 (COVID-19) (6). The outbreak of the virus has increased again in 2020 and affected many people around the world so far. The virus causes a mild respiratory illness in humans with flu-like symptoms (7). However, it has the ability of severe acute syndrome like SARS (8). Other important symptoms include fever, dizziness, and cough (9).

There is currently no vaccine or quite effective antiviral treatments for the new coronavirus (10). Several general methods are used to treat potential viral diseases and eradicate human pathogenic viruses, one of which is medicinal herbs. Herbs are suitable as an important source of chemical compounds for manufacturing and developing antiviral drugs. They can reduce the pathogenicity of the virus by neutralizing and 
inhibiting the uptake of the virus into the cell or by inhibiting virus replication in the cell $(11,12)$.

One of the herbs that may be effective in treating and preventing new coronavirus disease is the thyme herb. Thyme with the scientific name of Thymus vulgaris belongs to the mint family. This herb contains phenolic antioxidant compounds of eugenol, carvacrol, thymol, etc. $(13,14)$ (which leads to antispasmodic and antimicrobial effects), relieves contraction on smooth muscles, reduces bronchospasm, and relieves the symptoms of bronchitis, cough, and inflammation in some infectious diseases of the upper respiratory tract $(15,16)$. One of the mechanisms of action of thyme for treating respiratory disorders is a reduction in interleukin-1 $\beta$ (IL-1 $\beta$ ) and IL-8, which is activated by reducing the nuclear factor $-\kappa \mathrm{B}(\mathrm{NF}-\kappa \mathrm{B})$ level (17). Another important effect is the significant inhibitory effect of thyme essential oil on the proliferation of some viruses (18).

Persian medicine is one of the oldest traditional medicines, in which thyme has "Teriagh" effects. In Persian medicine, Teriagh refers to drugs or foods that have antitoxin and protective effects on main organs (such as the heart, liver, brain, etc.). Some believe it may be similar to antioxidants (19). In Persian medicine, thyme induces beneficial effects on the bronchodilator of the respiratory tract, cough, and upper respiratory tract infection. It is also used for treating diseases of the gastrointestinal tract, liver, and spleen. The relationship between the spleen and the reticuloendothelial and immune systems has been studied in various works $(\mathbf{2 0}$, 21). Therefore, considering the important effects of thyme on the respiratory system and its antiviral effect
$(22,23)$, we decided to investigate the effect of this plant on some symptoms of coronavirus.

\section{Materials and Methods}

First, the standard essential oil of T. vulgaris L. was prepared from a pharmacy Company. Then, a yes/no questionnaire was designed with a set of questions based on the patient's recovery process regarding symptoms such as fever, cough, coryza, dyspnea, dizziness, muscular pain, headache, sore throat, sputum, anorexia, weakness and lethargy, fatigue, chest wall pain, diarrhea, nausea, and vomiting. The inclusion criterion was as follows: Patients with COVID-19 hospitalized at Vali-e Asr Hospital, Zanjan, Iran. Exclusion criteria were as follows: Patients with respiratory and allergic diseases, pregnant women, and patients who did not consent to participate in the study, as well as those admitted to the intensive care unit (ICU).

This study was performed on the patients with COVID-19. For this purpose, 83 patients (hospitalized at Vali-e Asr Hospital, Zanjan, Iran, in 2020 due to coronavirus disease for one week) were first selected by a convenient sampling method (informed consent forms were obtained from all the patients and using block random assignment (random blocks; each block size =4)). Among them, 43 subjects were randomly assigned to the control group (which received only treatment package), and 40 entered the intervention group and received thyme essential oil (it should be noted that conventional medicine drugs were similar in both groups) (Figure 1).

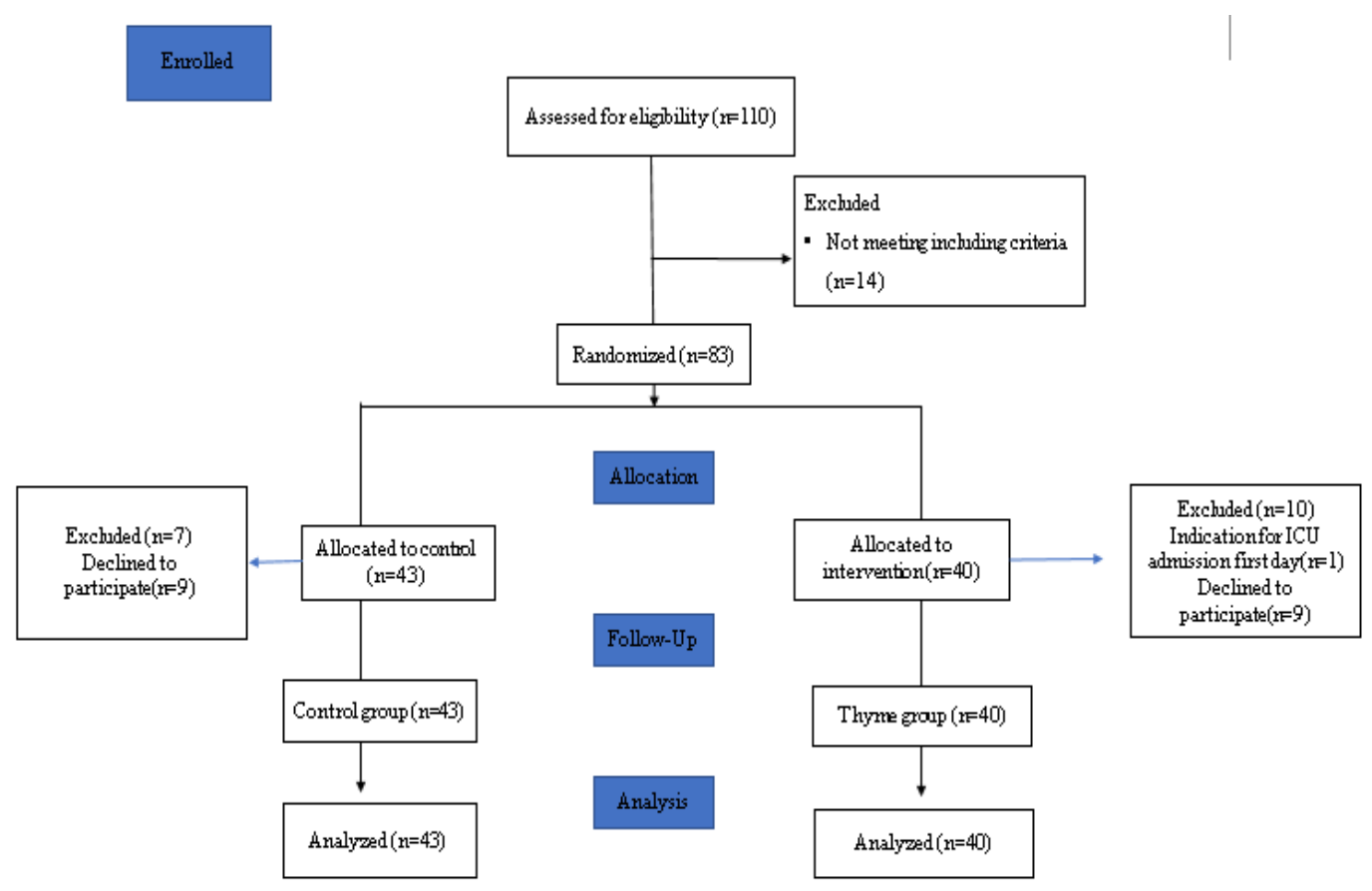

Figure 1. Consort flow diagram 
his study was approved with the Ethics Code IR.ZUMS.REC.1399.047 and registered in the Iranian Registry of Clinical Trials (IRCT) under the code IRCT20200506047319N1. Assuming the first-type statistical error of $5 \%$, the statistical power of $80 \%$, and the effectiveness of treatment of $20 \%$ in the control group and $50 \%$ in the intervention group. The number of the samples was calculated as 40 subjects per group using OpenEpi software.

Corona disease was confirmed and reported to be positive in a group of patients using reverse transcriptase-polymerase chain reaction (RT-PCR) test, and some others were hospitalized with the confirmation of lung involvement. In this study, the patients with underlying diseases, such as asthma, cough (due to allergies), heart disease, and so forth were excluded. Samples were divided into the control group (receiving routine medications prescribed by their doctors) and the intervention group (receiving thyme essential oil, $5 \mathrm{~mL}$ every eight $\mathrm{hr}$ for seven days); routine medications prescribed by their doctors. The questionnaire (as discussed in the previous section) was completed by the researcher and via asking questions from the patients. Then, with the consent of a group of patients, thyme was prescribed for them. Finally, one week after the first visit, the questionnaire was completed again to determine the effect of thyme on the mentioned symptoms (the therapeutic effect of this plant was defined as relieving cough and other symptoms after one week of treatment; complete improvement or mild symptoms were part of the recovery).

To evaluate the effectiveness of the drug on each of the mentioned symptoms, the results were analyzed using SPSS 22 (SPSS Inc., Chicago, Ill., USA). Descriptive results were presented as a number, percentage, median, and interquartile range. Chisquare, Mann-Whitney, and logistic regression tests were employed to compare the results between the groups. P-values less than 0.05 were considered statistically significant.

\section{Results}

This study was performed on patients with COVID19. Among them, 43 subjects were randomly assigned to the control group (which received no medication), and 40 received thyme essential oil and entered the intervention group (the conventional medicine drugs were similar in both groups) (Figure 1).

In this study, among 83 patients, 29 females $(67.4 \%)$ and 14 males $(32.6 \%)$ were enrolled in the control group with a mean age of 54.79 years old; also, 19 females $(57.5 \%)$ and 21 males $(52.5 \%)$ were enrolled in the control group with a mean age of 45.18 years old.

The results showed no significant difference in the symptoms between the control and intervention groups on the day before the intervention-except in dyspnea $(P<0.018)$ and sore throat $(P<0.022)$. Most of the patients had cough, dyspnea, muscular pain, headache, anorexia, weakness and lethargy, fatigue, fever, and chest wall pain $(P<0.05, P<0.01)$ (Table 1$)$. Due to the significant difference of sore throat and dyspnea in the week before the intervention, a statistician helped us and adjusted it.

Table 1. Frequency distribution of different symptoms in the study groups before the intervention (baseline)

\begin{tabular}{|c|c|c|c|c|}
\hline & Valuable & $\begin{array}{l}\text { Control } \\
\mathbf{N}(\%)\end{array}$ & $\begin{array}{c}\text { Intervention } \\
\mathbf{N}(\%)\end{array}$ & P-value \\
\hline \multirow{2}{*}{ Gender } & Female & $29(67.4 \%)$ & $19(57.8 \%)$ & \multirow{2}{*}{0.066} \\
\hline & Male & $14(32.6 \%)$ & $21(42.2 \%)$ & \\
\hline \multirow{2}{*}{ Fever } & Yes & $29(67.4 \%)$ & $19(47.5 \%)$ & \multirow{2}{*}{0.066} \\
\hline & No & $14(32.6 \%)$ & $21(52.5 \%)$ & \\
\hline \multirow{2}{*}{ Cough } & Yes & $41(95.3 \%)$ & $38(95 \%)$ & \multirow{2}{*}{0.941} \\
\hline & No & $2(4.7 \%)$ & $2(5 \%)$ & \\
\hline \multirow{2}{*}{ Coriza } & Yes & $6(14 \%)$ & $5(12.5 \%)$ & \multirow{2}{*}{0.845} \\
\hline & No & $37(86 \%)$ & $35(87.5 \%)$ & \\
\hline \multirow{2}{*}{ Dyspnea } & Yes & $33(76.7 \%)$ & $38(95 \%)$ & \multirow{2}{*}{0.018} \\
\hline & No & $10(23.3 \%)$ & $2(5 \%)$ & \\
\hline \multirow{2}{*}{ Dizziness } & Yes & $20(46.5 \%)$ & $17(42.5 \%)$ & \multirow{2}{*}{0.713} \\
\hline & No & $23(53.5 \%)$ & $23(57.5 \%)$ & \\
\hline \multirow{2}{*}{ Muscular pain } & Yes & $28(65.1 \%)$ & $31(77.5 \%)$ & \multirow{2}{*}{0.214} \\
\hline & No & $15(34.9 \%)$ & $9(22.5 \%)$ & \\
\hline \multirow{2}{*}{ Headache } & Yes & $29(67.4 \%)$ & $30(75 \%)$ & \multirow{2}{*}{0.448} \\
\hline & No & $14(32.6 \%)$ & $10(25 \%)$ & \\
\hline
\end{tabular}




\begin{tabular}{|c|c|c|c|c|}
\hline & Valuable & $\begin{array}{l}\text { Control } \\
\mathbf{N}(\%)\end{array}$ & $\begin{array}{c}\text { Intervention } \\
\mathbf{N}(\%)\end{array}$ & P-value \\
\hline \multirow{2}{*}{ Sore throat } & Yes & $14(32.6 \%)$ & $23(57.5 \%)$ & \multirow{2}{*}{0.022} \\
\hline & No & $29(67.4 \%)$ & $17(42.5 \%)$ & \\
\hline \multirow{2}{*}{ Sputum } & Yes & $15(34.9 \%)$ & $18(45 \%)$ & \multirow{2}{*}{0.347} \\
\hline & No & $28(65.1 \%)$ & $22(55 \%)$ & \\
\hline \multirow[t]{2}{*}{ Anorexia } & Yes & $27(62.8 \%)$ & $26(65 \%)$ & \multirow{2}{*}{0.834} \\
\hline & No & $16(37.2 \%)$ & $14(35 \%)$ & \\
\hline \multirow{2}{*}{ Weakness and lethargy } & Yes & $34(79.1 \%)$ & $29(72.5 \%)$ & \multirow{2}{*}{0.484} \\
\hline & No & $9(20.9 \%)$ & $11(27.5 \%)$ & \\
\hline \multirow{2}{*}{ Fatigue } & Yes & $31(72.1 \%)$ & $35(87.5 \%)$ & \multirow{2}{*}{0.082} \\
\hline & No & $12(27.9 \%)$ & $5(12.5 \%)$ & \\
\hline \multirow{2}{*}{ Chest wall pain } & Yes & $26(60.5 \%)$ & $26(65 \%)$ & \multirow{2}{*}{0.670} \\
\hline & No & $17(39.5 \%)$ & $14(35 \%)$ & \\
\hline \multirow{2}{*}{ Diarrhea } & Yes & $7(16.3 \%)$ & $10(25 \%)$ & \multirow{2}{*}{0.325} \\
\hline & No & $36(83.7 \%)$ & $30(75 \%)$ & \\
\hline \multirow{2}{*}{ Vomit } & Yes & $16(37.2 \%)$ & $20(50 \%)$ & \multirow{2}{*}{0.334} \\
\hline & No & $27(62.8 \%)$ & $20(50 \%)$ & \\
\hline
\end{tabular}

Based on the results, improvement rate in the thymereceiving group was significantly higher than that of the control group. In terms of the symptoms of fever, only one subject had fever after consuming thyme. In other words, the fever symptom in the intervention group improved compared to the control group with $P<0.027$. Also, 38 patients $(95 \%)$ with cough $(P<0.001), 36$ patients $(90 \%)$ with dyspnea $(P<0.001)$, 35 patients $(87.5 \%)$ with dizziness $(P<0.003), 37$ patients $(92.5 \%)$ with muscular pain $(P<0.001), 34$ patients $(85 \%)$ with headache $(P<0.001), 40$ patients $(100 \%)$ with sore throat $(P<0.001), 28$ patients $(72 \%)$ with anorexia $(P<0.001), 23$ patients $(57.5 \%)$ with weakness and lethargy $(P<0.001), 38$ patients $(95 \%)$ with fatigue $(P<0.001)$, and 39 patients $(97.5 \%)$ with chest wall pain $(P<0.001)$ had improvement in the thyme group $(P<0.05, P<0.01, P<0.001)$ (Table 2$)$.

Table 2. Frequency distribution of different symptoms in the study groups after the intervention; P-values are reported as crude and adjusted by age using logistic regression analysis

\begin{tabular}{|c|c|c|c|c|c|c|}
\hline Valuable & & $\begin{array}{l}\text { Control } \\
\mathbf{N}(\%)\end{array}$ & $\begin{array}{c}\text { Intervention } \\
\mathbf{N}(\%)\end{array}$ & P-value & OR $(95 \%)$ & $\begin{array}{c}\text { Adjusted } \\
\text { P-value }\end{array}$ \\
\hline \multirow{2}{*}{ Fever } & Yes & $8(18.6 \%)$ & $1(2.5 \%)$ & \multirow{2}{*}{0.066} & \multirow{2}{*}{$0.08(0.01-0.8)$} & \multirow{2}{*}{$<0.027$} \\
\hline & No & $35(81.4 \%)$ & $39(97.5 \%)$ & & & \\
\hline \multirow{2}{*}{ Cough } & Yes & $29(67.4 \%)$ & $2(5 \%)$ & \multirow{2}{*}{0.941} & \multirow{2}{*}{$0.03(0.005-0.13)$} & \multirow{2}{*}{$<0.001$} \\
\hline & No & $14(32.6 \%)$ & $38(95 \%)$ & & & \\
\hline \multirow{2}{*}{ Coriza } & Yes & $7(16.3 \%)$ & $3(7.5 \%)$ & \multirow{2}{*}{0.845} & \multirow{2}{*}{$0.5(0.12-2.3)$} & \multirow{2}{*}{0.391} \\
\hline & No & $35(83.7 \%)$ & $37(92.5 \%)$ & & & \\
\hline \multirow{2}{*}{ Dyspnea } & Yes & $29(67.4 \%)$ & $4(10 \%)$ & \multirow{2}{*}{0.018} & \multirow{2}{*}{$0.04(0.01-0.16)$} & \multirow{2}{*}{$<0.001$} \\
\hline & No & $14(32.6 \%)$ & $36(90 \%)$ & & & \\
\hline \multirow{2}{*}{ Dizziness } & Yes & $18(41.9 \%)$ & $5(12.5 \%)$ & \multirow{2}{*}{0.713} & \multirow{2}{*}{$0.14(0.04-0.47)$} & \multirow{2}{*}{$<0.003$} \\
\hline & No & $25(58.1 \%)$ & $35(87.5 \%)$ & & & \\
\hline \multirow{2}{*}{ Muscular pain } & Yes & $33(76.7 \%)$ & $3(7.5 \%)$ & \multirow{2}{*}{0.214} & \multirow{2}{*}{$0.02(0.005-0.1)$} & \multirow{2}{*}{$<0.001$} \\
\hline & No & $10(23.3 \%)$ & $37(92.5 \%)$ & & & \\
\hline
\end{tabular}




\begin{tabular}{|c|c|c|c|c|c|c|}
\hline Valuable & & $\begin{array}{l}\text { Control } \\
\mathbf{N}(\%)\end{array}$ & $\begin{array}{c}\text { Intervention } \\
\mathbf{N}(\%)\end{array}$ & P-value & OR $(95 \%)$ & $\begin{array}{c}\text { Adjusted } \\
\text { P-value }\end{array}$ \\
\hline \multirow{2}{*}{ Headache } & Yes & $21(48.8 \%)$ & $6(15 \%)$ & \multirow{2}{*}{0.448} & \multirow{2}{*}{$0.13(0.04-0.4)$} & \multirow{2}{*}{$<0.001$} \\
\hline & No & $22(51.2 \%)$ & $34(85 \%)$ & & & \\
\hline \multirow{2}{*}{ Sore throat } & Yes & $11(25.6 \%)$ & $0(0 \%)$ & \multirow{2}{*}{0.022} & \multirow{2}{*}{ undefined } & \multirow{2}{*}{$<0.001$} \\
\hline & No & $32(74.4 \%)$ & $40(100 \%)$ & & & \\
\hline \multirow{2}{*}{ Sputum } & Yes & $9(20.9 \%)$ & $11(27.5 \%)$ & \multirow{2}{*}{0.347} & \multirow{2}{*}{$1.8(0.6-5.3)$} & \multirow{2}{*}{0.285} \\
\hline & No & $34(79.1 \%)$ & $29(72.5 \%)$ & & & \\
\hline \multirow[t]{2}{*}{ Anorexia } & Yes & $31(72.1 \%)$ & $12(30 \%)$ & \multirow{2}{*}{0.834} & \multirow{2}{*}{$0.15(0.05-0.4)$} & \multirow{2}{*}{$<0.001$} \\
\hline & No & $12(27.9 \%)$ & $28(70 \%)$ & & & \\
\hline \multirow{2}{*}{$\begin{array}{l}\text { Weakness and } \\
\text { lethargy }\end{array}$} & Yes & $39(90.7 \%)$ & $17(42.5 \%)$ & \multirow{2}{*}{0.484} & \multirow{2}{*}{$0.07(0.02-0.25)$} & \multirow{2}{*}{$<0.001$} \\
\hline & No & $4(9.3 \%)$ & $23(57.5 \%)$ & & & \\
\hline \multirow{2}{*}{ Fatigue } & Yes & $30(69.8 \%)$ & $2(5 \%)$ & \multirow{2}{*}{0.082} & \multirow{2}{*}{$0.02(0.004-0.1)$} & \multirow{2}{*}{$<0.001$} \\
\hline & No & $13(30.2 \%)$ & $38(95 \%)$ & & & \\
\hline \multirow{2}{*}{ Chest wall pain } & Yes & $20(46.5 \%)$ & $1(2.5 \%)$ & \multirow{2}{*}{0.670} & \multirow{2}{*}{$\begin{array}{c}0.03(0.003- \\
0.22)\end{array}$} & \multirow{2}{*}{0.001} \\
\hline & No & $23(53.5 \%)$ & $39(97.5 \%)$ & & & \\
\hline \multirow{2}{*}{ Diarrhea } & Yes & $2(4.7 \%)$ & $2(5 \%)$ & \multirow{2}{*}{0.325} & \multirow{2}{*}{$1.1(0.14-9)$} & \multirow{2}{*}{0.928} \\
\hline & No & $41(95.3 \%)$ & $38(95 \%)$ & & & \\
\hline
\end{tabular}

Table 3 shows that the results of the experiments on the day before the intervention in the control and intervention groups (in the first round of case history) were not significantly different. Due to the significant age in the week before the intervention, the analysis was performed by removing the effect of age.

Table 3. Age and laboratory test results before the intervention in the study groups

\begin{tabular}{|cccc} 
Valuable & Control & Intervention & P-value \\
\hline Age & Median (IQR) & Median (IQR) & 0.009 \\
\hline BUN & $58(24)$ & $43(26)$ & 0.189 \\
Cr & $14.4(7.75)$ & $13.4(3.9)$ & 0.678 \\
Ca & $0.8(0.3)$ & $0.9(0.25)$ & 0.322 \\
\hline LDH & $8.65(0.85)$ & $9(1.33)$ & 0.111 \\
WBC & $467(214.5)$ & $361(211.5)$ & 0.633 \\
\hline RBC & $5.4(3.7)$ & $5.65(3.425)$ & 0.814 \\
PIt & $4.6(1.122)$ & $4.7(1.000)$ & 0.453 \\
Lym & $182(79)$ & $162(83)$ & 0.374 \\
\hline Neu & $24.25(19.13)$ & $24.5(13)$ & 0.070 \\
Na & $64.65(27.6)$ & $69(18.8)$ & 0.465 \\
\hline K & $140.5(7)$ & $140(6)$ & 0.612 \\
Mg & $4(0.69)$ & $4.1(0.63)$ & 0.833 \\
\hline
\end{tabular}


Table 4 shows the test results of the patients in the control and thyme-receiving groups after one week of the completed period. The results demonstrated that blood urea nitrogen (BUN) of the thyme-receiving group significantly decreased compared to the control group $(P<0.004)$, and calcium increased significantly $(P<0.034)$. Also, lymphocyte count increased significantly $(P<0.000)$, and neutrophil decreased $(P<0.001)(P<0.01, P<0.001)$.

Table 4. Test results one week after the intervention in the study groups

\begin{tabular}{cccc} 
Valuable & Control & Intervention & P-value \\
\hline BUN & $13.30(6.65)$ & Median (IQR) & $<0.004$ \\
Cr & $0.90(0.3)$ & $9.50(3.38)$ & 0.480 \\
Ca & $8(1.15)$ & $0.90(0.3)$ & 0.034 \\
\hline LDH & $464.5(294.75)$ & $8.80(1.5)$ & 0.626 \\
WBC & $6.15(2.25)$ & $486(538)$ & 0.380 \\
RBC & $4.55(1.15)$ & $5.65(3.33)$ & 0.483 \\
PIt & $209.5(154.75)$ & $4.6(1)$ & 0.455 \\
Lym & $20(21.75)$ & $182(125)$ & $<0.000$ \\
Neu & $65.25(30)$ & $37.4(13.1)$ & $<0.001$ \\
Na & $140(4)$ & $51.7(20.6)$ & 0.572 \\
K & $4(0.73)$ & $140(5)$ & 0.377 \\
Mg & $2.6(0.27)$ & $4(0.9)$ & 0.060 \\
\hline
\end{tabular}

\section{Discussion}

Viral infections account for $60 \%$ of human infections, and 1.5 million deaths from respiratory infections are reported worldwide each year. However, recently, only one new strain of the coronavirus, called COVID-19, has infected many countries around the world due to the rapid transmission of the disease and has caused panic among the world. It has severely suppressed the respiratory system and killed many people over several months around the world $(7,9,24)$. That is why many studies have been done in this field. This work was also performed on patients with COVID-19 to investigate the therapeutic effect of thyme essential oil on the main symptoms of these patients. The results of this study showed that thyme had a positive effect on symptoms, such as fever, cough, dyspnea, dizziness, muscular pain, anorexia, weakness and lethargy, and fatigue, and significantly reduced the severity of symptoms. It also significantly increased the lymphocyte count, decreased the neutrophil count, BUN, and increased the calcium.

Some studies have represented similar results. For instance, the research conducted by Karina Schonknecht et al. (on the effect of the active compound of thymol on upper respiratory tract infection with the effects of reducing cough and dyspnea and shortening the duration of the disease) showed the medicinal effect of thyme; primrose extracts were comparable to the synergistic effect of thymol with artificial ambroxol and its safety was proven (25). In addition, the antibacterial, antimicrobial, and antioxidant effects of thyme (which strengthens the immune system) have been demonstrated (26). Other studies have shown that fresh thyme has 29 active ingredients and the highest level of antioxidants, especially thymol $(30 \%)$ and carvacrol (32\%), which are the main components of the plant. This is why this plant is widely used in folk medicine for treating various diseases, such as the gastrointestinal tract and respiratory disorders (such as bronchopulmonary disease, etc.) $(17,27,28)$. Also, this plant has a muscle relaxant effect, and several studies have shown the effect of thyme essential oil for treating cough and respiratory diseases, including pertussis, tuberculosis, bronchitis, and diseases of the respiratory tract (29-33).

Our study showed its effect on muscular pain, chest wall pain, and headache. Thyme stimulates the immune system and increases the number of lymphocytes (34). Another study examined the analgesic effects of three Moroccan thyme species. The results of this study showed significant inhibition of thyme in response to formalin pain (35). The analgesic effect of thyme may 
be due to a decrease in the inflammatory factors of IL$1 \beta$ and IL-8, decrease in extracellular $\mathrm{Ca}^{2}$ levels, and increase in the cilia beating frequency of the airway epithelium (17).

Also, thyme is used for indigestion, asthma, and diarrhea, as well as for indigestion with bloating, gonorrhea, scabies, and cataracts. The aqueous extract showed high antiviral activity against herpes simplex virus-1 (HSV-1), herpes simplex virus-2 (HSV-2), and acyclovir-resistant strain of HSV-1. The results of a study conducted by Akbar S et al. In 2020 showed that Thyme extract significantly reduces the production and expression of inflammatory mediators, tumor necrosis factor $\alpha$ (TNF- $\alpha)$, IL-1 $\beta$, IL-6, and carvacrol are reported to activate Peroxisome Proliferator Activator Receptor- $\alpha$ (PPAR $\alpha$ ) and Peroxisome Proliferator Activator Receptor- $\gamma$ (PPAR $\gamma)$ suppress Cyclooxygenase-2 (COX-2) expression, and inhibit acetylcholinesterase (AChE) (36).

\section{Limitations}

Active ingredients of the drug should have been identified and flow cytometer tests should have been measured for the patients. But, it was not feasible due to limited financial resources.

\section{Conclusion}

Results of this study showed that thyme as a medicinal plant with antioxidant properties is widely used in some respiratory diseases in Persian medicine (20). It can affect the respiratory system (cough, shortness of breath, etc.), muscle pain, fatigue, weakness and lethargy, fever, and so forth. Thyme increases lymphocytes and, thus, could strengthen the immune system. On the other hand, according to previous studies, thyme has an antiviral effect. It also has inhibitory effects on some interleukins that may have immunomodulatory effects. It also has inhibitory effects on some interleukins that may have immunomodulatory effects. Therefore, thyme has probably a positive effect on the healing process of corona disease.

\section{Ethical considerations}

Ethical issues (Including plagiarism, informed consent, misconduct, data fabrication and/or falsification, double publication and/or submission, redundancy, etc.) have been completely observed by the authors.

\section{Acknowledgment}

The vice chancellor for research of Zanjan Universityof Medical Sciences approved the current study with ethicalcode: IR.ZUMS.REC.1399.047. We thank the research deputy of Zanjan faculty of medical sciences for financially supporting this project.

\section{Funding and support}

This research resulted from an independent research without receiving any financial support.

\section{Conflict of Interest}

Authors declared no conflict of interest.

\section{References}

1. Lau SK, Lee $\mathrm{P}$, Tsang AK, et al. Molecular epidemiology of human coronavirus OC43 reveals evolution of different genotypes over time and recent emergence of a novel genotype due to natural recombination. J Virol.2011;85(21):11325-37. [DOI:10.1128/JVI.05512-11]

2. Woo PC, Lau SK, Chu C-m, et al. Characterization and complete genome sequence of a novel coronavirus, coronavirus HKU1, from patients with pneumonia. J Virol.2005;79(2):884-95. [DOI:10.1128/JVI.79.2.884-895.2005]

3. Peiris JSM, Chu C-M, Cheng VC-C, et al. Clinical progression and viral load in a community outbreak of coronavirus-associated SARS pneumonia: a prospective study.Lancet. 2003;361(9371):176772. [DOI:10.1016/S0140-6736(03)13412-5]

4. WHO. Summary of probable SARS cases with onset of illness from 1 November 2002 to 31 July 2003. 2003.

5. Organization WHO. Middle East respiratory syndrome coronavirus (MERS-CoV). 2019.

6. Le Chang Y, Lunan Wang. Coronavirus disease 2019: Coronaviruses and blood safety. Trans Med Rev. 2020;34(2):75-80. [DOI:10.1016/j.tmrv.2020.02.003]

7. Balboni A, Battilani M, Prosperi SJM-QJoMS. The SARS-like coronaviruses: the role of bats and evolutionary relationships with SARS coronavirus. New

Microbiol.2012;35(1):1. [DOI:10.1100/2012/989514]

8. Peiris J, Lai S, Poon L, et al. Coronavirus as a possible cause of severe acute respiratory syndrome.Lancet 2003;361(9366):1319-25. [DOI:10.1016/S0140-6736(03)13077-2]

9. Wu F, Zhao S, Yu B, et al. A new coronavirus associated with human respiratory disease in China.Nature. 2020;579(7798):265-9. [DOI:10.1038/s41586-020-2008-3] 
10. Lu H. Drug treatment options for the 2019-new coronavirus (2019-nCoV). Biosci Trends. 2020;14(1):69-71. [DOI:10.5582/bst.2020.01020]

11. González-Molina E, Moreno DA, García-Viguera CJSh. Comparison of 'Verna'lemon juice quality for new ingredients and food products. Scientia horticulturae. [DOI:10.1016/j.scienta.2008.11.010]

12. Tang LI, Ling AP, Koh RY, Chye SM, Voon KGJBc. Screening of anti-dengue activity in methanolic extracts of medicinal plants. BMC Complement Altern Med. 2012;12(1):3. [DOI:10.1186/1472-6882-12-3]

13. Merchán Arenas DR, Muñoz Acevedo A, Vargas Méndez LY, Kouznetsov VVJSp. Scavenger activity evaluation of the clove bud essential oil (Eugenia caryophyllus) and eugenol derivatives employing ABTS+• decolorization.Sci Pharm. 2011;79(4):779-92. [DOI:10.3797/scipharm.110911]

14. Farahani M. Antiviral effect assay of Thymus Kotschyanus on HSV-1 multiplication.J Alborz Univ Med Sci. 2017;6(4):269-75. [DOI:10.29252/aums.6.4.269]

15. Fleming TJMEC. PDR ${ }^{\circledR}$ for Herbal Medicines ${ }^{\mathrm{TM}}$. Edited by Fleming T. New Jersey. 2000:224-5.

16. Organization WHO. WHO monographs on selected medicinal plants: World Health Organization; 1999.

17. Nabissi M, Marinelli O, Morelli MB, et al. Thyme extract increases mucociliary-beating frequency in primary cell lines from chronic obstructive pulmonary disease patients. Biomed Pharmacother. 2018;105:1248-53.

[DOI:10.1016/j.biopha.2018.06.004]

18. Kordali S KR, Mavi A, Cakir A, Ala A, Yildirim A. Determination of the chemical composition and antioxidant activity of the essential oil of Artemisia dracunculus and of the antifungal and antibacterial activities of Turkish Artemisia absinthium, A. J Agri Food Chem. 2005;53(24):9452-8. [DOI:10.1021/jf0516538]

19. Sardai S, Fallahi F, Emadi F, et al. Pharmaceut Sci.

20. Mh A. Makhzan al-Advieh. Tehran: Tehran University of Medical Sciences. 2009;328.

21. Lewis SM, Williams A, Eisenbarth SC. Structure and function of the immune system in the spleen. Sci Immunol. 2019;4(33). [DOI:10.1126/sciimmunol.aau6085]

22. Santoyo S, Jaime L, García-Risco M, Lopez-Hazas M, Reglero GJIC, Products. Supercritical fluid extraction as an alternative process to obtain antiviral agents from thyme species. Indust Crops Products 2014;52:475-80 [DOI:10.1016/i.indcrop.2013.10.028]
23. Lenz E, Müller C, Mostafa A, et al. Authorised medicinal product Aspecton ${ }^{\circledR}$ Oral Drops containing thyme extract KMTv24497 shows antiviral activity against viruses which cause respiratory infections. J Herbal Med. 2018;13:2633. [DOI:10.1016/i.hermed.2018.02.003]

24. Organization WHO. Almost a quarter of all disease caused by environmental exposure. 2006.

25. Schönknecht K, Krauss H, Jambor J, Fal AMJWl. Treatment of cough in respiratory tract infectionsthe effect of combining the natural active compounds with thymol. Wiadomosci lekarskie. 2016;69(6):791.

26. Salehi B, Mishra AP, Shukla I, et al. Thymol, thyme, and other plant sources: Health and potential uses. Phytother Res.2018;32(9):1688-706. [DOI:10.1002/ptr.6109]

27. Komaki A, Hoseini F, Shahidi S, Baharlouei NJJot, medicine c. Study of the effect of extract of Thymus vulgaris on anxiety in male rats. J Trad Complement Med. 2016;6(3):257-61. [DOI:10.1016/j.jtcme.2015.01.001]

28. Mohamed A, Omar AJN, Science. A study to find thyme oil dose that kill $50 \%$ of mice and minimal dose that kill all mice and maximum non-lethal dose.Nat Sci. 2013;11(12):52-3.

29. Büechi S, Vögelin R, von Eiff MM, Ramos M, Melzer JJCMR. Open trial to assess aspects of safety and efficacy of a combined herbal cough syrup with ivy and thyme. Complement Med Res. 2005;12(6):328-32. [DOI:10.1159/000088934]

30. Gruenwald J, Graubaum HJ, Busch RJA. Efficacy and tolerability of a fixed combination of thyme and primrose root in patients with acute bronchitis. Arzneimittelforschung. 2005;55(11):669-76. [DOI:10.1055/s-0031-1296916]

31. Lis-Balchin M, Hart SJJoe. A preliminary study of the effect of essential oils on skeletal and smooth muscle in vitro. J Ethnopharmacol. 1997;58(3):1837. [DOI:10.1016/S0378-8741(97)00103-7]

32. Van Den Broucke C, Lemli JJPW. Spasmolytic activity of the flavonoids from Thymus vulgaris. Pharmaceutisch Weekblad. 1983;5(1):9-14. [DOI:10.1007/BF01959645]

33. Dashti-Zadeh F, Mahmoodi MM. The effect of aqueous and alcoholic extracts of thyme, eucalyptus, chamomile and fennel on virulence factors of Escherichia Coli, causative agent of urinary tract infection.J Alborz Univ Med Sci. 2017;6(4):257-68. [DOI:10.29252/aums.6.4.257]

34. Soltani M, Sheikhzadeh N, Ebrahimzadeh-Mousavi $\mathrm{H}$, Zargar AJJoF, Science A. Effects of Zataria multiflora essential oil on innate immune responses of common carp (Cyprinus carpio). J Fisheries Aquatic Sci. 2010;5(4):191-9. 
35. Elhabazi K, Ouacherif A, Laroubi A, et al. Analgesic activity of three thyme species, Thymus satureioides, Thymus maroccanus and Thymus leptobotrys. African J Microbiol Res. 2008;2(10):262-7.
36. Akbar S. Thymus vulgaris L.(Lamiaceae). Handbook of 200 Medicinal Plants: Springer; 2020. p. 1795-810. [DOI:10.1007/978-3-030-168070_185]

\section{How to Cite This Article:}

Sardari S, Mobaiend A, Ghassemifard L, Kamali K, Khavasi N. Therapeutic Effect of Thyme (Thymus Vulgaris) Essential Oil on Patients with COVID19: A Randomized Clinical Trial. J Adv Med Biomed Res. 2021; 29 (133) :83-91

Download citation:

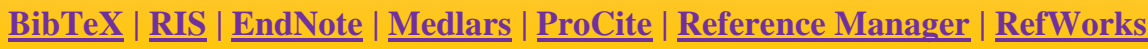

\section{Send citation to:}

6. Mendeley 2 Zotero (0) RefWorks $\underline{\text { RefWorks }}$ 